\title{
Static and dynamic characterization of poly-SiGe Grating Light Valves
}

\author{
S. Rudra, D. Van Thourhout \\ Photonics Research Group, INTEC \\ Ghent University-IMEC \\ Ghent, Belgium
}

\author{
A. Witvrouw, J. De Coster, R. Van Hoof \\ IMEC \\ Leuven, Belgium
}

\begin{abstract}
We present the fabrication and the characterization results of poly-SiGe grating light valves showing excellent contrast. We also discuss the different dimensional parameters that affect the switching time of the device through squeeze film damping.
\end{abstract}

Keywords- Poly-SiGe, grating light valve, squeeze film damping

\section{INTRODUCTION}

Grating Light Valve ${ }^{1,2}$ (GLV) display pixels are diffraction gratings, consisting of electrostatically movable fixed-fixed microbeams. Non-actuated coplanar beams behave like a mirror giving specular reflection. After actuation, the alternate movable beams are deflected downwards and the grating starts diffracting, which turns the pixel ON. GLV based displays ${ }^{3}$ can provide a huge improvement in contrast, resolution and switching speed over other types of MEMS based displays. At the same time poly-SiGe based MEMS are gaining increasing interest because they can be post-processed above $\mathrm{CMOS}^{4}{ }^{5}$. Poly-SiGe layers have a lower deposition temperature $\left(\sim 450^{\circ} \mathrm{C}\right)$ compared to Poly-Si $\left(\sim 800^{\circ} \mathrm{C}\right)$ but still possess the necessary mechanical properties and reliability required for MEMS.

Hence in this work we use poly-SiGe layers for developing GLVs and characterized their overall optical and mechanical performance. We were able to produce sufficient tensile stress within the poly-SiGe microbeams resulting in excellent flat structures, which is one of the primary requirements for a GLV to work efficiently and reach high contrast. Due to the small airgap between the microbeams and the underlying substrate and due to fast operating speed of the GLVs, squeezed film damping $^{6}$ becomes the dominant mechanism affecting its dynamic response. We show the variation in the amount of damping with different dimensions of the microbeams and the resulting effect on the switching time of the individual pixels.

\section{DEVICE FABRICATION}

The CVD deposited structural SiGe layer was grown on top of a Ti/TiN adhesion layer with a $\mathrm{SiH}_{4}: \mathrm{GeH}_{4}$ ratio of $0.9: 1$ and a $\mathrm{B}_{2} \mathrm{H}_{6}\left(1 \%\right.$ in $\left.\mathrm{H}_{2}\right)$ flow ratio of $90 \mathrm{sccm}$ at a wafer temperature of $\sim 450^{\circ} \mathrm{C}$. Following roughness reduction of the $\mathrm{SiGe}$ layer by Chemical Mechanical Polishing (CMP), extra layers consisting of $5 \mathrm{~nm} \mathrm{SiC}$ and $30 \mathrm{~nm} \mathrm{Al}$ were added. Finally the samples were released with a 5 step release recipe in a vapor of $\mathrm{HF}$ and ethanol with a ratio of $4: 5$. Beams with lengths of 50 $\mu \mathrm{m}, 75 \mu \mathrm{m}, 100 \mu \mathrm{m}$ and $150 \mu \mathrm{m}$ were fabricated each with periods of $3.0 \mu \mathrm{m}, 4.2 \mu \mathrm{m}$ and $5 \mu \mathrm{m}$. A fixed gap of $0.3 \mu \mathrm{m}$ among the consecutive microbeams was maintained. We used two different sacrificial layer thicknesses of $400 \mathrm{~nm}$ and 800 $\mathrm{nm}$ for our devices. Figure 1 shows a SEM picture of a fabricated GLV device.

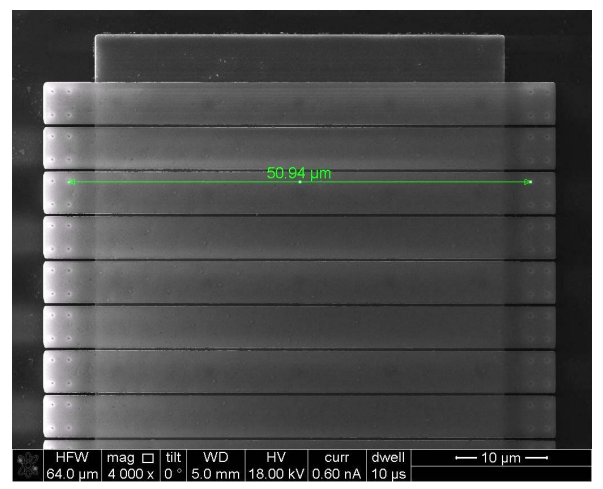

Fig. 1. Scanning Electron Microscope view of a GLV device consisting of alternately moving and fixed microbeams with length of $50 \mu \mathrm{m}$.
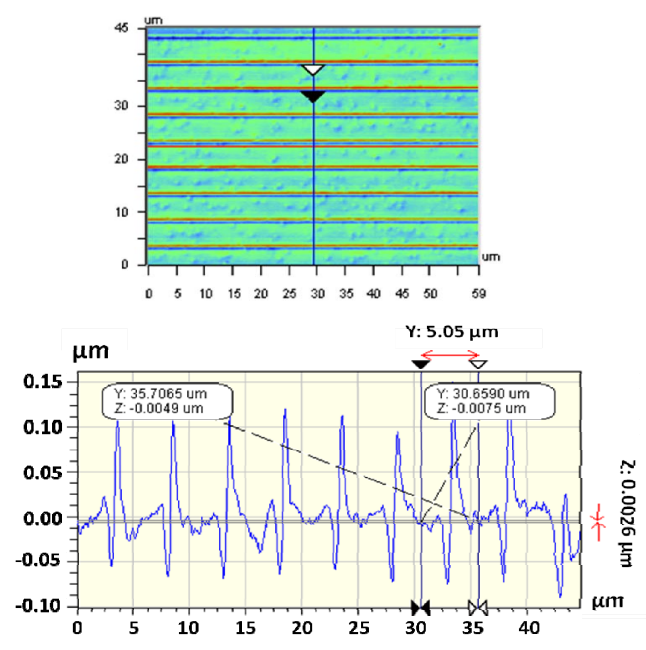

Fig. 2. Optical profile of a 100 um long non-actuated GLV device as measured with WYKO.

\section{STATIC MEASUREMENTS}

One of the stringent requirements for a GLV to function well is to achieve sufficient flatness of the microstructures. Any height difference among consecutive microbeams will result in scattering and increases the noise in the dark state. The profile of a $100 \mu \mathrm{m}$ long grating device in non-actuated condition as obtained with a WYKO optical profilometer is shown in Fig. 2. A height difference as low as $2.6 \mathrm{~nm}$ among consecutive microbeams was obtained. Figure 3 shows the 
diffraction efficiency as function of the applied voltage for devices with different length and for a wavelength of $633 \mathrm{~nm}$ (He-Ne laser). As a result of the excellent flatness control of the devices, a contrast of $\sim 1250: 1$ could be obtained consistently for these devices with a maximum efficiency of $67 \%$ for the $\pm 1^{\text {st }}$ order of diffracted light, in line with simulations for these devices.

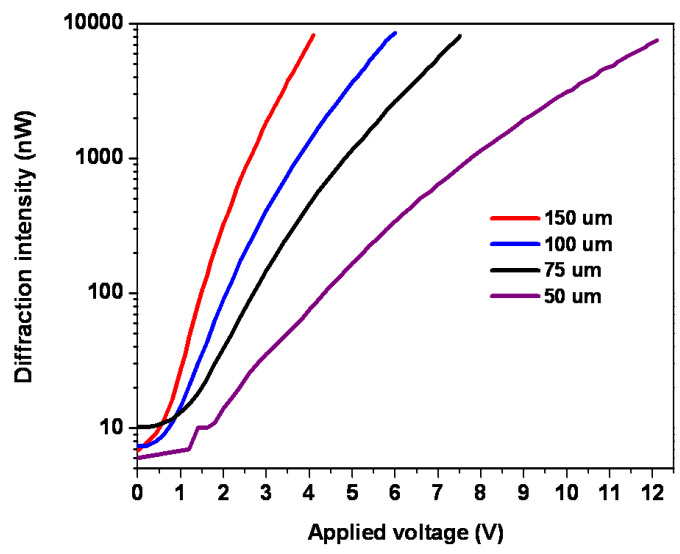

Fig. 3. Analog response of GLV devices showing an excellent optical response.

\section{EFFECT OF SQUEEZE FILM DAMPING}

As the GLV beams can be approximated by a mass-springdamper model working below the cut-off frequency ${ }^{7}$ associated with the squeeze film theory, viscous drag due to the surrounding fluid becomes the dominant damping mechanism in these structures. The viscous damping coefficient for parallel plate movement is given by:

$$
\mathrm{c}_{\mathrm{v}} \propto \mu \mathrm{ww}^{3} / \mathrm{h}_{0}{ }^{3}
$$

Hence the damping ratio of the system is defined as:

$$
\mathrm{b}=\mathrm{c}_{\mathrm{v}} / 2 \mathrm{~m} \omega_{\mathrm{r}}
$$

where, $\mu$ is the viscous coefficient of the surrounding fluid, $\mathrm{h}_{0}$ is the height of the airgap, $w$ is the width, 1 is the length, $m$ is the mass and $\omega_{\mathrm{r}}$ is the natural vibration frequency of the beams.

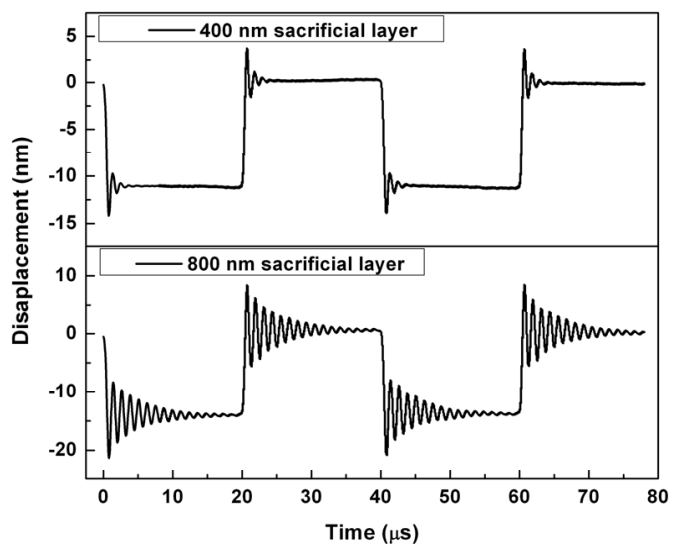

Fig. 4. Variation in settling time with change in airgap for a $50 \mu \mathrm{m}$ long and 4.7 $\mu \mathrm{m}$ wide microbeam.

If the damping is too low then the resonance effects result into ringing of the microbeams when a step voltage is applied. If the damping is too large then also the switching time is degraded. We used laser doppler vibrometry to characterize the response of the GLVs to a square wave pulse train.

Fig. 4 and 5 show the variation in settling time (equilibrium \pm $2 \%$ ) with the change in dimensional parameters. We decreased the airgap and increased the width of the microbeams to maximize the damping in the system. A maximum resonance frequency of $1 \mathrm{MHz}$ was obtained for the $50 \mu \mathrm{m}$ long microbeams. With variation in the dimensions, a minimum settling time of $2.2 \mu \mathrm{s}$ was achieved for these microbeams corresponding to a width of $4.7 \mu \mathrm{m}$ and an airgap of $400 \mathrm{~nm}$.

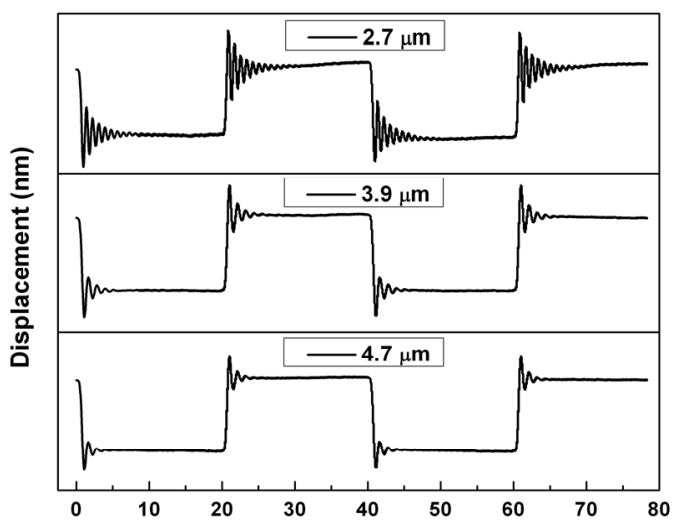

Fig. 5. Variation in settling time with change in width for a $50 \mu \mathrm{m}$ long microbeam.

\section{DISCUSSIONS}

We demonstrated a fully operational poly-SiGe based GLV device. A maximum contrast of 1250:1 was obtained for our GLVs. We varied the airgap and the width of the microbeams to increase the damping and hence reduced the settling time of the devices to a minimum value of $2.2 \mu \mathrm{s}$.

\section{ACKNOWLEDGMENT}

We would like to thank the IWT to support this work through the SBO Gemini project.

\section{REFERENCES}

[1] D. Bloom, "The Grating Light Valve: Revolutionizing Display Technology," Projection Displays III Symposium, SPIE Proceedings, 3013, pp. 165-171, 1997.

[2] D. T. Amm and R. W. Corrigan, "Grating Light Valve Technology: Update and Novel Applications", SID Symposium Digest for Technical Papers, vol. 29, pp. 29-32, May 1998.

[3] J.I. Trisnadi, C.B. Carlisle, and R. Monteverde. "Overview and applications of Grating Light Valve ${ }^{\mathrm{TM}}$ based optical write engines for high-speed digital imaging”, Proc. SPIE, vol. 5348, pp 1-13, 2004.

[4] A. Witvrouw, "CMOS-MEMS integration today and tomorrow", Scripta Materialia, vol. 59, pp. 945-949, 2008.

[5] R. Jablonski, M. Turkowski and R. Szewczyk, "Recent Advances in Mechatronics", Springer Berlin Heidelberg, 2007, pp. 521-525.

[6] M.H. Bao. Analysis and design principles of MEMS devices. Elsevier Science, 2005, pp. 124-136.

[7] M. Bao and H. Yang. Squeeze film air damping in MEMS. Sensors and Actuators A: Physical, vol. 136(1), pp. 3-27, 2007. 